\title{
Pânico Moral e a Abordagem de Gênero nas Escolas
}

Regina Rodrigues Costa, Universidade Federal de Pernambuco

O presente trabalho faz uma construção histórica dos reflexos sociais que desencadearam o pânico moral à abordagem de gênero nas escolas brasileiras, com o objetivo de analisar os fatores que motivaram os projetos de lei que tentam censurar tais conteúdos dos currículos escolares. Para isso, adotamos como marco os desdobramentos decorrentes desde o lançamento do programa Brasil sem Homofobia em 2004, onde analisamos suas intenções e ações. Outro marco abordado é a divulgação do Caderno Escola sem Homofobia, que culmina no atual ataque as discussões de gênero na escola, que se expressa através da propositura de diversos projetos de lei que objetivam proibir a adoção da temática nas instituições de ensino. Além disso, analisamos qual a real importância da discussão de gênero no ambiente escolar e os argumentos contrários a essa temática. Por fim, o trabalho reafirma a necessidade de defender uma educação voltada ao respeito às diferenças e a promoção da dignidade da pessoa humana, sem ceder aos preceitos patriarcais, morais e religiosos.

PALAVRAS-CHAVE: Pânico moral. Gênero nas escolas. Escola sem partido. Direitos Humanos. 


\section{Introdução}

Desde o ano de 2014 eclodiram vários debates relacionados à discussão de gênero nas escolas. Esses debates se expressaram através de projetos de lei que apresentavam como proposta alterar a Lei de Diretrizes e Bases da Educação Nacional (LDB) para proibir disciplinas obrigatórias, complementares ou até mesmo facultativas que abordassem discussão sobre "gênero" e/ou "orientação sexual", no debate sobre a Base Nacional Curricular Comum (BNCC), onde diversas propostas foram apresentadas no intuito de suprimir a menção aos termos "gênero" e "orientação sexual" (supressão que foi acatada na terceira versão da BNCC, aprovada pelo Conselho Nacional de Educação e homologada pelo Ministério de Educação) ${ }^{1}$, entre outros.

Mas um dos acontecimentos recentes que propiciou o retorno dessa vigília conservadora, embasada numa moral cristã e em defesa da "família heteronormativa" 2 foi o pânico moral que se alastrou em decorrência de uma divulgação feita de forma deturpada do Caderno Escola sem Homofobia, no ano de 2010.

Apesar dos preceitos morais estarem presentes na escola, regulando de forma direta ou indireta o currículo desde o século XIX, e do debate sobre a moralidade religiosa influenciar o ambiente educacional ser ponto de questionamentos desde a primeira metade do século XX, o contexto que vivenciamos hoje tem outras peculiaridades, que serão demonstradas a partir dos marcos estabelecidos nesse artigo.

Debater sobre essa temática é de extrema urgência e importância diante do cenário que se vivencia atualmente no Brasil, onde se prega retrocessos de direitos fundamentais, discursos de ódio, cerceamento das liberdades de expressão e perseguição aos debates sobre gênero.

A partir de uma construção histórica dos reflexos sociais que desencadearam o pânico moral à discussão relacionada a gênero no ambiente educacional, o objetivo do presente trabalho é analisar os fatores que desencadearam os projetos de lei que tentam censurar o debate sobre essa temática nos currículos escolares, além de argumentar

1 Dados disponíveis em: http://www.deolhonosplanos.org.br/bncc-aprovada-generoorientacao-sexual/. Acesso em 28 de jun. 2018.

2 Para Warner apud Britzman (1996, p. 79) heteronormatividade é a obsessão com a sexualidade normalizante, através de discursos que descrevem a situação homossexual como desviante. 
a importância da abordagem de gênero e/ou sexualidade nos espaços de ensino formal.

\section{O Programa Brasil sem Homofobia e o ataque conservador}

No ano de 2004 o Governo Federal, em parceria com os movimentos sociais de gays, lésbicas, transgêneros e bissexuais (GLTB)3, lançou o programa Brasil sem Homofobia, voltado ao combate à violência e à discriminação contra pessoas LGBT e a promoção da cidadania homossexual.

A cartilha elaborada a época reflete as intenções do programa:

Um dos objetivos centrais deste programa é a educação e a mudança de comportamento dos gestores públicos. Buscamos a atitude positiva de sermos firmes e sinceros e não aceitarmos nenhum ato de discriminação e adotarmos um "não à violência" como bandeira de luta. (BRASIL, 2004, p. 07)

O programa previa ações para diversos componentes, como: Articulação da Política de Promoção dos Direitos de Homossexuais; Legislação e Justiça; Cooperação Internacional; Direito à Segurança: combate à violência e à impunidade; Direito à Educação: promovendo valores de respeito à paz e a não-discriminação por orientação sexual; Direito à Saúde: consolidando um atendimento e tratamentos igualitários; Direito ao Trabalho: garantindo uma política de acesso e de promoção da não-discriminação por orientação sexual; Direito à Cultura: construindo uma política de cultura de paz e valores de promoção da diversidade humana; Política para a Juventude; Política para as Mulheres; Política contra o Racismo e a Homofobia.

Em relação ao componente de educação, tinham-se como programa de ações efetivas as seguintes:

Elaborar diretrizes que orientem os Sistemas de Ensino na implementação de ações que comprovem o respeito ao cidadão e à não-discriminação por orientação sexual;

Fomentar e apoiar curso de formação inicial e continuada de professores na área da sexualidade;

3 Na época GLTB era a sigla utilizada. Hoje, a sigla utilizada pelos movimentos sociais é LGBTI+, que abarca lésbicas, gays, bissexuais, travestis, transexuais, transgêneros e intersexuais. 
Formar equipes multidisciplinares para avaliação dos livros didáticos, de modo a eliminar aspectos discriminatórios por orientação sexual e a superação da homofobia;

Estimular a produção de materiais educativos (filmes, vídeos e publicações) sobre orientação sexual e superação da homofobia;

Apoiar e divulgar a produção de materiais específicos para a formação de professores;

Divulgar as informações científicas sobre sexualidade humana;

Estimular a pesquisa e a difusão de conhecimentos que contribuam para o combate à violência e à discriminação de GLTB;

Criar o Subcomitê sobre Educação em Direitos Humanos no Ministério da Educação, com a participação do movimento de homossexuais, para acompanhar e avaliar as diretrizes traçadas. (BRASIL, 2004, pp. 22 e 23)

Como um exemplo de concretização dessas ações, foi criado o Projeto Escola sem Homofobia, financiado pelo Ministério da Educação (MEC), sob orientação da Secretaria de Educação Continuada, Alfabetização e Diversidade (SECAD), que é vinculada ao MEC e com a colaboração de entidades da sociedade civil. Esse projeto elaborou o material "Caderno Escola sem Homofobia", que em sua apresentação dispõe:

Este Caderno e o kit de ferramentas educacionais que o acompanha compõem a base teórica e material com que se pretende dar o passo inicial para a promoção e garantia de uma escola livre de homofobia. Podem ser implementados através de um programa de médio ou longo prazo, como também de oficinas temáticas. Orientam-se pelos princípios da igualdade e respeito à diversidade, da equidade, da laicidade do Estado, da universalidade das políticas, da justiça social. Sua principal meta é contribuir para o reconhecimento da diversidade de valores morais, sociais e culturais presentes na sociedade brasileira, heterogênea e comprometida com os direitos humanos e a formação de uma cidadania que inclua de fato os direitos das pessoas LGBT. (2010)

O caderno, que foi divulgado no ano de 2010, com a finalidade de quebrar a concepção didática heteronormativa, conservadora, binária e promover uma concepção inclusiva, em consonância com a promoção dos Direitos Humanos, da igualdade e do direito à diferença, possuía como instrumentos pedagógicos textos, dinâmicas, materiais audiovisuais, além de ter como proposta a inclusão de toda a comunidade escolar - gestores/as, professores/as, pais, mães, grêmios, 
associações e outros -, nas discussões de gênero, sexualidade e combate a homofobia.

A necessidade da abordagem de uma educação voltada para o combate de preconceitos é refletida nos resultados de uma pesquisa denominada Preconceito e Discriminação no Ambiente Escolar4, realizada em 2009 pela Fundação Instituto de Pesquisas Econômicas (Fipe) a pedido do Instituto Nacional de Estudos e Pesquisas Educacionais Anísio Teixeira (Inep), realizado em 501 escolas, com participação de 18.599 pessoas, dentre elas: estudantes, pais e mães, professores/as e funcionários/as da rede pública de todos os Estados do País, revelou que $87,3 \%$ dos entrevistados possuem preconceito com relação à orientação sexual.

Porém, a divulgação desse caderno no ano de 2010 foi transformada num pânico moral pela bancada parlamentar conservadora. O Caderno Escola sem Homofobia foi divulgado como "kit de combate à homofobia nas escolas", e teve seu nome desconfigurado a partir de uma discussão levantada na sessão da Câmara dos Deputados em 30 de novembro de 2010, quando o deputado federal Jair Bolsonaro se referiu ao material como "maior escândalo que tomou conhecimento até hoje", pontuou que o kit era "um incentivo ao homossexualismo e a promiscuidade" 5. Após as incitações feitas, a bancada evangélica se apropriou das discussões e passou a se referir ao material como "kit gay".

\section{O pânico moral e a proibição da abordagem de gênero nas escolas}

Miskolci (2007, p. 11), analisa que o pânico moral se dá quando uma ação ou uma categoria que foge do padrão normativo é identificada, e o que representa uma pequena quebra em relação ao convencional, recebe um julgamento e uma forte reação coletiva, o autor, ao analisar a conceituação de Cohen, nos traz que quando ocorre um pânico moral:

4 Disponível em: https://www.fea.usp.br/fea/noticias/painel-pesquisa-mostra-quepreconceito-na-escola-existe-e-prejudica-rendimento.

5 A fala completa do parlamentar pode ser visualizada em: https://www.youtube.com/ watch?v=ONfPCxKdGT4. 
Uma condição, um episódio, uma pessoa ou um grupo de pessoas passa a ser definido como um perigo para valores e interesses societários; sua natureza é apresentada de uma forma estilizada e estereotipada pela mídia de massa; as barricadas morais são preenchidas por editores, bispos, políticos e outras pessoas de Direita; especialistas socialmente aceitos pronunciam seus diagnósticos e soluções; recorre-se a formas de enfrentamento ou desenvolvem-nas. Então a condição desaparece, submerge ou deteriora e se torna mais visível. Algumas vezes, o objeto do pânico é absolutamente novo e outras vezes é algo que existia há muito tempo, mas repentinamente ganha notoriedade. Algumas vezes o pânico passa e é esquecido, exceto no folclore e na memória coletiva. Outras vezes ele tem repercussões mais sérias e duradouras e pode produzir mudanças tais como aquelas em política legal e social ou até mesmo na forma como a sociedade se compreende. (COHEN, 1972, p. 09 apud MISKOLCI, 2007, p. 11)

Pode-se afirmar que o pânico moral em relação à abordagem de gênero nas escolas brasileiras tem seu início no ano de 2010, com o episódio ocorrido na Câmara dos Deputados, anteriormente mencionado, onde o parlamentar Jair Bolsonaro afirma diversas vezes que o material "Caderno Escola sem Homofobia", elaborado para combater a discriminação e a homofobia nas escolas, por ele pontuado como um incentivo ao 'homossexualismo'6 e a promiscuidade, seria destinado a crianças de 6,7 , e 8 anos, inclusive fazendo um forte apelo aos pais, anunciando que seus filhos teriam contato nas escolas com vídeos que ensinam as crianças a beijarem na boca de outras do mesmo sexo e manter relações sexuais.

Acontece que, na verdade o material seria destinado para os/as professores/as das escolas de ensino médio que tivessem interesse na temática, ou seja, seu uso não era obrigatório, tampouco o destinatário direto era os estudantes ou incitava a prática de relações sexuais (homoafetivas ou não) entre os estudantes.

O episódio repercutiu por todo Brasil e uma campanha foi encabeçada por Jair Bolsonaro, que lançou o seguinte panfleto:

6 Conforme Carrano (2013), em 17 de maio de 1990, a Organização Mundial da Saúde (OMS) retirou a homossexualidade da lista de doenças mentais do Código Internacional de Doenças. A decisão também eliminou o uso do sufixo 'ismo', desvinculando a orientação sexual da ideia de enfermidade [...] Cinco anos antes, o Conselho Federal de Psicologia (CFP) brasileiro já havia deixado de classificar a homossexualidade como desvio sexual. 
Ilustração 1: Panfleto contra a campanha de promoção da cidadania e diversidade

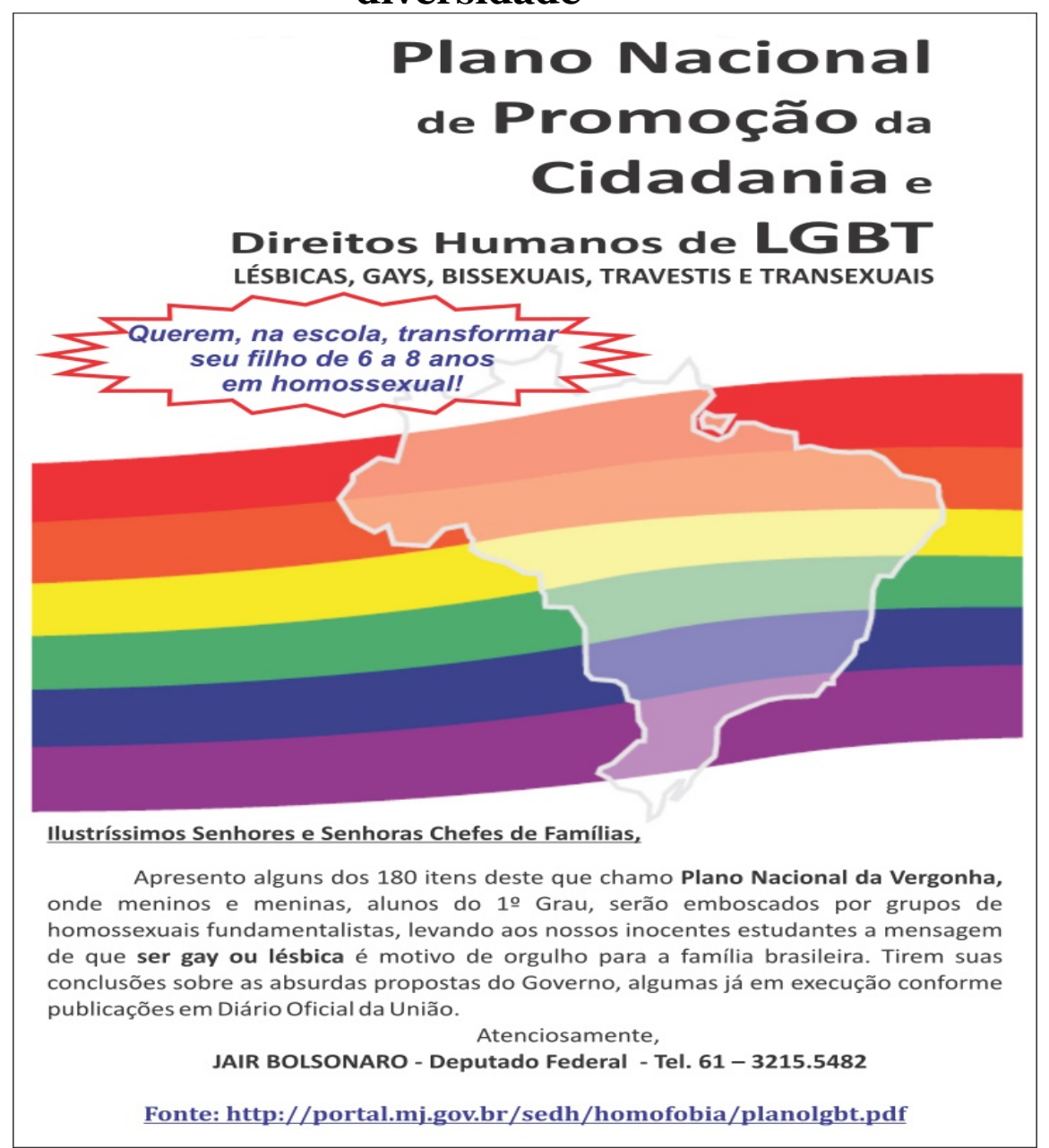

Disponível em: http://familiabolsonaro.blogspot.com/2011/o5/ bolsonaro-sofre-heterofobia-de-senadora.html

A divulgação deturpada do kit de combate à homofobia nas escolas, sob a imagem de "kit gay" que irá "transformar, na escola, seu filho de 6 a 8 anos em homossexual" fez com que o governo suspendesse todo o material pouco tempo depois, tendo em vista que a polêmica incomodou até mesmo os parlamentares progressistas, que em sua maioria não saíram em defesa da campanha pró-cidadania e diversidade?.

7 O deputado Jean Wyllys, a época do PSOL-RJ, afirmou que a postura do Ministério da Educação ao suspender o material foi covarde. 
Mas o episódio não foi suficiente para por fim a abordagem de gênero nas escolas. A partir de então, a bancada evangélica criou uma perseguição ao que denominam "ideologia de gênero", o conceito representa mais uma distorção do que os estudiosos denominam teoria de gênero, que nada mais é do que o estudo sobre gênero e sua construção na sociedade.

Desde 2015 temos dois elementos novos voltados à perseguição dos projetos relacionados à orientação sexual, gênero, diversidade e afins. O primeiro deles é a constituição oficial da Frente Parlamentar Evangélica do Congresso Nacional8, o segundo é que a perseguição contra a abordagem de gênero passa a se dar através da via legislativa ativa, com propositura de projetos de lei.

Atualmente, já foram apresentados 46 Projetos de Lei (PL's)9, seja a nível federal, estadual ou municipal, que proíbem a discussão da temática de gênero ou orientação sexual na escola, ou ainda em materiais didáticos, o mais conhecido desses PL's é o 1859/2015, que pretende acrescentar ao art. $3^{\circ}$ da Lei de Diretrizes e Bases da Educação (LDB) o parágrafo único, determinando que:

Art. $3^{0}[\ldots]$

Parágrafo único: A educação não desenvolverá políticas de ensino, nem adotará currículo escolar, disciplinas obrigatórias, ou mesmo de forma complementar ou facultativa, que tendam a aplicar a ideologia de gênero, o termo 'gênero' ou 'orientação sexual (BRASIL, 2015).

Para os defensores da "ideologia de gênero", essa significa "uma ideologia antifamília, uma tentativa de transformar os jovens em gays e lésbicas, um ataque à família" (PENNA, 2017, p. 45), o que representa uma falsa concepção, pois a discussão sobre gênero tem, a bem da verdade, o papel humano e social de desconstruir padrões de desigualdade, de machismo, de homofobia, de prevenção de estereótipos

8 Requerimento 3424 em 21 de outubro de 2015. Disponível em: http://www.camara.leg.br/ internet/deputado/Frente_Parlamentar/53658-integra.pdf. Acesso em 02 de jul. 2018.

9 O levantamento inicial foi realizado por Fernanda Moura em sua dissertação de mestrado "Escola sem Partido": Relações entre Estado, Educação e Religião e os impactos no Ensino de História" no ano de 2016, que resultou na construção do quadro panorama do escola sem partido no Brasil. O quadro versa sobre PL's que tramitam com a temática de proibição de gênero ou que estabelecem o programa escola sem partido. Para construção do presente trabalho, levou-se em conta apenas os PL's relacionados à gênero. A tabela está disponível em: https://professorescontraoescolasempartido.wordpress.com/vigiando-os-projetos-delei/ e teve sua última atualização em o8/01/2018. 
sobre feminilidade, masculinidade, de trazer à tona representações reais de família - família homoafetiva, monoparental, coparental e outras.

Sendo assim, discutir gênero no ambiente escolar representa discutir direitos humanos, representa também uma promoção à dignidade da pessoa humana, ao fortalecer uma política de reconhecimento e de respeito às diferenças, onde se educa para coibir as discriminações de qualquer natureza, partindo da visão Paulo Freiriana da educação como um dos instrumentos para a transformação social.

\section{A importância da discussão sobre gênero nas escolas}

Britzman (1996, p. 79-80) observa que há alguns mitos contraditórios sobre a divisão homo/hetero, um deles está associado ao medo que as pessoas heterossexuais, que imaginam sua identidade sexual como "normal" e "natural", de que a mera menção da homossexualidade vá encorajar e promover as práticas homossexuais, de modo a fazer com que os/as jovens integrem as comunidades gays e lésbicas.

É esse mito que sustenta um dos argumentos a favor da proibição de abordar conteúdos ligados a gênero nos espaços escolares. Mas a adoção desse argumento coloca a heterossexualidade como única expressão da orientação sexual - ou como a única "correta", dentro de um padrão religioso e conservador -, desprezando as diversas outras formas existentes na sociedade.

Fugir da discussão de gênero no ambiente escolar reforça a invisibilidade de pessoas LGBTI+, o que representa uma forma de violência e discriminação e pode trazer desdobramentos sociais graves, além de aumentar a vulnerabilidades desses grupos. Negar as possibilidades diversas de orientação sexual recai no que Martin e Hetrick (1988) identificam como um dos tipos de isolamento entre jovens gays e lésbicas, que seria $\mathrm{o}$ isolamento cognitivo, onde $\mathrm{o}$ conhecimento sobre as práticas e as histórias dos gays e das lésbicas não estão disponíveis (tampouco sobre outras expressões de orientação sexual para além da homossexualidade, a exemplo dos/as bissexuais, pansexuais, assexuais ou de identidade de gênero, a exemplo dos/as transexuais). 
Para Britzman (1996, p. 93), no âmbito da educação e da pedagogia faz-se necessário compreender as sexualidades em tantos termos quanto possíveis e ainda assim conseguir assinalar as sexualidades como algo que é moldado na linguagem e na conduta. É preciso construir pedagogias que envolvam todas as pessoas e possibilitar que haja menos discursos normalizadores dos corpos, dos gêneros, das relações sociais, da afetividade e do amor.

No Brasil, os parâmetros curriculares nacionais ${ }^{10}$ que versam sobre orientação sexual, entendem que esta engloba as relações de gênero, o respeito a si mesmo e ao outro e à diversidade de crenças, valores e expressões culturais existentes numa sociedade democrática e pluralista, prevê que sobre a postura do/a educador/a:

Em relação às questões de gênero, por exemplo, os professores devem transmitir, por sua conduta, a valorização da equidade entre os gêneros e a dignidade de cada um individualmente. Ao orientar todas as discussões, eles próprios respeitam a opinião de cada aluno e, ao mesmo tempo, garantem o respeito e a participação de todos, explicitando os preconceitos e trabalhando pela não-discriminação das pessoas (BRASIL, 1997)

Outro documento, publicado em 2013, são as orientações técnicas de educação em sexualidade para o cenário brasileiro da Organização das Nações Unidas para a Educação, a Ciência e a Cultura (UNESCO), que tem como intenção orientar o desenvolvimento de currículos localmente adaptados. O material apresenta tópicos e objetivos de aprendizagem sobre educação em sexualidade, organizados de acordo com conceitos-chave e tópicos propostos para cada faixa etária. Temos como conceitos-chave: relacionamentos, valores, atitudes e habilidades, cultura, sociedade e direitos humanos, desenvolvimento humano, comportamento sexual, saúde sexual e reprodutiva.

Em sua introdução, as orientações dispõem que:

A educação em sexualidade pode ser entendida como toda e qualquer experiência de socialização vivida pelo indivíduo ao longo de seu ciclo vital, que lhe permita posicionar-se na esfera social da sexualidade. A educação em sexualidade está presente em todos os espaços de socialização - família, escola, igreja, pares, trabalho, mídia -, mas ocorre de forma pulverizada, fragmentada e desassociada de um plano

10 Conforme Altmann (2001, p. 579) "os PCNs pretendem ser um referencial fomentador da reflexão sobre os currículos escolares, uma proposta aberta e flexível, que pode ou não ser utilizada pelas escolas na elaboração de suas propostas curriculares". 
de sociedade inclusiva baseada nos direitos humanos. Portanto, tornase relevante a atuação do sistema educacional na tarefa de reunir, organizar, sistematizar e ministrar essa dimensão da formação humana (UNESCO, 2013, p. 07).

Sendo assim, as questões de gênero e/ou sexualidade e suas apresentações na escola representam uma garantia democrática de respeito, de equidade, de promoção da não-discriminação por orientação sexual, identidade de gênero e outras, de maneira a desconstruir uma cultura de imposição heteronormativa.

Nessa esteira, Britzman (2000) afirma que "sexualidade tem muito a ver com a capacidade para a liberdade e com os direitos civis e que o direito a uma informação adequada é parte daquilo que vincula a sexualidade tanto com o domínio imaginário quanto com o domínio público”.

Britzman (2000) também analisa que o currículo da sexualidade deve estar mais próximo à dinâmica da sexualidade e ao cuidado de si, deve também ser construído de forma dinâmica, para além dos limites do conhecimento disciplinado e do mecanismo defensivo do discurso escolar oficial. A partir da premissa de que a sexualidade é qualquer lugar, a autora afirma que a partida é uma conversa e uma produção generosa de uma sociabilidade que se recusa a se justificar através do consolo da fixação de um lugar próprio.

Ou seja, ao invés de representar mais um ambiente de opressão, de exclusão, de isolamento, o ambiente escolar precisa representar um ambiente acolhedor, dinâmico, que represente a todos e todas. É esse o papel dos debates de gênero e/ou sexualidade nas escolas: discutir e questionar um padrão heteronormativo de expressão única das masculinidades e feminilidades, de maneira a demonstrar as diferenças como naturais, como construções fluídas dos indivíduos, sem imposição de papéis e/ou condutas.

\section{Considerações Finais}

$\mathrm{O}$ ataque moral-conservador vai além da abordagem de gênero nas escolas, os grupos políticos e sociais que proíbem campanhas contra a homofobia são os mesmos que se posicionaram de forma contrária ao casamento homoafetivo, que lançam campanhas contra o estatuto da diversidade sexual, defendem a existência da "cura gay" e até mesmo se 
posicionam a favor de medidas extremas, como estupro corretivo, assassinato de homossexuais e etc.

O pânico moral que permeia as situações ligadas a gênero, orientação sexual, sexualidade, direitos humanos ou qualquer outra questão que mexa direta ou indiretamente na estrutura patriarcal, conservadora, moral, cristã, tende a surgir sempre que essas situações representarem conquistas de direitos dos grupos socialmente vulneráveis. Nesse aspecto, faz-se necessário que as medidas institucionais sejam garantidas como políticas públicas de promoção da dignidade da pessoa humana, e que não cedam às pressões de alas parlamentares e/ou de grupos sociais contrários a promoção da pluralidade, da cidadania e da diversidade.

Outro foco de discussão no presente trabalho se deu em relação às abordagens de gênero, diferenças e sexualidade na escola, nesse aspecto entendemos que a educação comprometida com os valores da dignidade da pessoa humana e com o respeito à diversidade representa mais do que um direito, representa uma necessidade e encontra assento no prefácio da Declaração Universal dos Direitos Humanos (DUDH).

Nessa lógica, tanto as disposições do PCN sobre orientação sexual como as orientações técnicas de educação em sexualidade da UNESCO representam um grande avanço e são importantes instrumentos norteadores sobre como a temática deve ser abordada nos espaços educacionais.

\section{Referências}

ALTMANN, Helena. Orientação sexual nos parâmetros curriculares nacionais. Revista Estudos Feministas, v. 2, 2001.

BRASIL. Congresso. Câmara dos Deputados. Projeto de Lei 1859, de

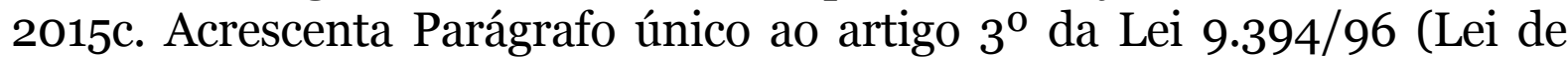
Diretrizes e Bases da Educação). Brasília-DF, apresentação em 10 de junho de 2015. Disponível em: https://www.camara.gov.br/proposicoesWeb/ fichadetramitacao?idProposicao=1302894. Acesso em: 20 de jun. 2018.

BRASIL, Parâmetros Curriculares Nacionais/Ensino Fundamental: Orientação sexual. Brasília: Ministério da Educação, 1997.

BRITZMAN, Déborah. Curiosidade, sexualidade e currículo. In: LOURO, Guacira Lopes (org). O corpo educado: pedagogias da sexualidade. 
Tradução dos artigos: Tomaz Tadeu da Silva. Belo Horizonte: Autêntica, 2000.

- O que é essa coisa chamada amor: identidade homossexual, educação e currículo. In Educação \& Realidade (1996). V. 21 (1), jan./jun.

CARRANO, Paulo. Há 23 anos a homossexualidade deixava de ser considerada pela OMS uma doença mental. Disponível em: http:// www.emdialogo.uff.br/content/ha-23-anos-homossexualidade-deixavade-ser-considerada-pela-oms-uma-doenca-mental. Acesso: 05 de jul. 2018.

COHEN, Stanley. Folk Devils and Moral Panics: The Creation of Mods and Rockers. London, MacGibbon \& Kee, 1972.

Caderno Escola sem Homofobia (2010). Disponível em: http:// www.acaoeducativa.org.br/fdh/wp-content/uploads/2015/11/kit-gayescola-sem-homofobia-mec1.pdf. Acesso: 02 de jun. 2018.

CONSELHO Nacional de Combate à Discriminação. Brasil Sem Homofobia: Programa de combate à violência e à discriminação contra GLTB e promoção da cidadania homossexual. Brasília: Ministério da Saúde, 2004.

MARTIN, A. D.; HETRICK, E. The Stigmatization of the Gay and Lesbian Adolescent. Journal of Homosexuality 15 (1-2): 163 - 183. 1988.

MISKOLCI, Richard. Pânicos morais e controle social: reflexões sobre o casamento gay. Cadernos Pagu, Campinas, p. 101-128, janeiro-junho 2007.

MOURA, Fernanda Pereira de. "Escola Sem Partido": Relações entre Estado, Educação e Religião e os impactos no Ensino de História. 2016, 188 f. Dissertação (Mestrado) Programa de Pós-Graduação em Ensino de História, Instituto de História, Universidade Federal do Rio de Janeiro UFRJ, Rio de Janeiro.

PENNA, Fernando de Araujo. O Escola sem Partido como chave de leitura do fenômeno educacional. In: FRIGOTTO, Gaudêncio (Org.) Escola "sem" partido: esfinge que ameaça a educação e a sociedade brasileira. Rio de Janeiro: UERJ, LPP, 2017.

UNESCO. Orientações técnicas de educação em sexualidade para o cenário brasileiro: tópicos e objetivos de aprendizagem. Brasília, 2013. 


\section{Pánico Moral y el Enfoque de Género en las Escuelas}

RESUMEN: El presente trabajo hace una construcción histórica de los reflejos sociales que desencadenaron el pánico moral al abordaje de género en las escuelas brasileñas, con el objetivo de analizar los factores que desencadenaron los proyectos de ley que intentan censurar tales contenidos de los currículos escolares. Para ello, adoptamos como marco los desdoblamientos resultantes desde el lanzamiento del programa Brasil sin Homofobia en 2004, donde analizamos sus intenciones y acciones. Otro marco abordado es la divulgación del Cuaderno Escuela sin Homofobia, que culmina en el actual ataque las discusiones de género en la escuela, que se expresa a través de la proposición de diversos proyectos de ley que objetivan prohibir la adopción de la temática en las instituciones de enseñanza. Además, analizamos cuál es la real importancia de la discusión de género en el ambiente escolar y los argumentos contrarios a esa temática. Por último, el trabajo reafirma la necesidad de defender una educación orientada al respeto a las diferencias y la promoción de la dignidad de la persona humana, sin ceder a los preceptos patriarcales, morales y religiosos.

Palabras Clave: Pánico moral. Género en las escuelas. Escuela sin partido.

Regina Rodrigues COSTA

Bacharela em Direito - UFPB; Especialista em Direito Homoafetivo e de Gênero - UNISANTA; Mestranda em Direitos Humanos - PPGDH/UFPE.

Recebido em: 04/12/2018

Aprovado em: 17/10/2019 